\title{
A FATAL CASE OF BERIBERI IN A CHILD IN ENGLAND
}

\author{
BY \\ E. C. AllibONE, M.D., and H. S. BAAR, M.D.
}

(From the Children's Hospital, Birmingham)

\begin{abstract}
Beriberi is rarely observed in England. From time to time sporadic cases appear in adults. Jones and Bramwell (1939), Konstam and Sinclair (1940) and others have reported cases due to alcoholism. Bates (1941) recorded the disease in a young woman who neglected herself. Even on the continent, Pyke (1945) in Vienna, and Ellis (1945) in Brussels make no mention of beriberi having occurred during the enemy occupation, though famine oedema appeared in adults and to a less extent in children. The precedence, in nutritional deficiency in Europe, of oedema over beriberi fits in with what has been observed in Birmingham and is to be seen in this case. The probable explanation is that vegetables and bread are relatively richer in thiamin than in protein.

That a child should die of beriberi in England is sufficiently uncommon to warrant publication. Apart from the rarity, the present case presents some unusual findings. Although chronic, with histologically demonstrable changes in the nervous system, the main clinical features were due to the involvement of the heart. The latter showed in the post-mortem examination such changes as would be expected if a tyrically acute beriberi heart as described by Wenckebach (1934) were to survive for a longer period.
\end{abstract}

\section{Case report}

B. P., born February 15, 1941, was originally admitted to the Children's Hospital, Birmingham, on February 14, 1944 with the following history.

He was the youngest of a family of three of whom the eldest died in infancy of bronchopneumonia, the second having congenital heart disease. The parents were healthy.

Feeding had been by the breast until the age of fourteen months. Since then the diet had contained nearly a pint of milk daily, three to four eggs a week, but neither meat, fish nor greens. After weaning, a teaspoon of cod-liver oil was given in the morning and a cup of orange juice at night. Walking commenced at eleven months and talking five months later.

His teeth were cut ' with bronchitis,' since when he had been subject to a cough. Apart from measles when a year old his general health had remained satisfactory until two weeks before admission when he developed diarrhoea. Two days before coming into hospital the legs and feet became swollen, stiff and painful.
On admission he was seen to be a broad-featured, sallow non-toxic child. The hands were podgy, the feet and legs oedematous. Chvostek's sign was present. There were no other abnormal signs. The urine was normal.

Blood analysis on February 17, 1944, gave the following figures:-

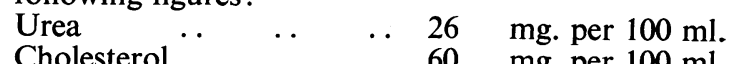
Cholesterol .. $\quad$.. $\quad \ldots \quad 60 \quad$ mg. per $100 \mathrm{ml}$.

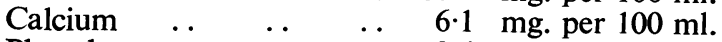
Phosphorus.. $\quad$.. $\quad . . \quad 3.4 \mathrm{mg}$. per $100 \mathrm{ml}$.

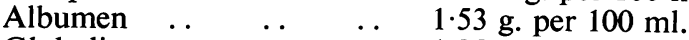

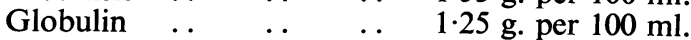
Fibrinogen ... $\quad$.. $\quad \ldots \quad 0.49 \mathrm{~g}$. per $100 \mathrm{ml}$.

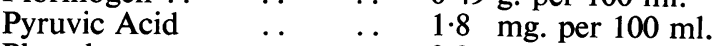
Phosphatase $\quad$. $\quad$. $99.2 \mathrm{mg}$. of P. liberated by $100 \mathrm{ml}$. of serum in 3 hours at $37^{\circ} \mathrm{C}$.

The case was considered to be one of nutritional deficiency aggravated by the diarrhoea. He was given an ordinary diet supplemented by calcium chloride, thiamin, iron and vitamin D. The oedema gradually disappeared. On March 24, 1944, the plasma proteins were:-

Albumen, 3.32; globulin, 2.17; fibrinogen, 0.34 g. per $100 \mathrm{ml}$.

He was discharged with advice as to diet which now contained an egg every day as well as a pint of milk, but he still did not take either meat, fish or greens. Marmite was given as a vitamin B supplement. He was well and symptom-free, apart from his chronic cough, for four months when the feet began to ache and swell. He remained active for a further four days, then became quiet, and was admitted to hospital the following day (July 25, 1944).

He now looked exhausted, and was orthopnoeic with grunting respiration and a loose cough. The legs and abdominal wall were oedematous, and the liver enlarged to a distance of three fingers' breadths below the costal margin. In the chest were signs of an asthmatical bronchitis which tended to obscure the heart sounds. The apex beat was not palpable, the pulse was 120 , feeble and irregular. The heart sounds were very soft. The tendon reflexes were obtained with difficulty. Blood analysis on July 26 , 1944 gave the following figures:-

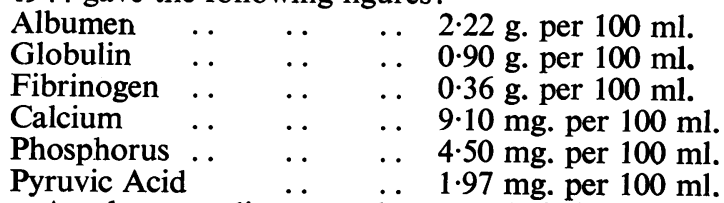
An electrocardiogram taken on admission (fig. 1) 


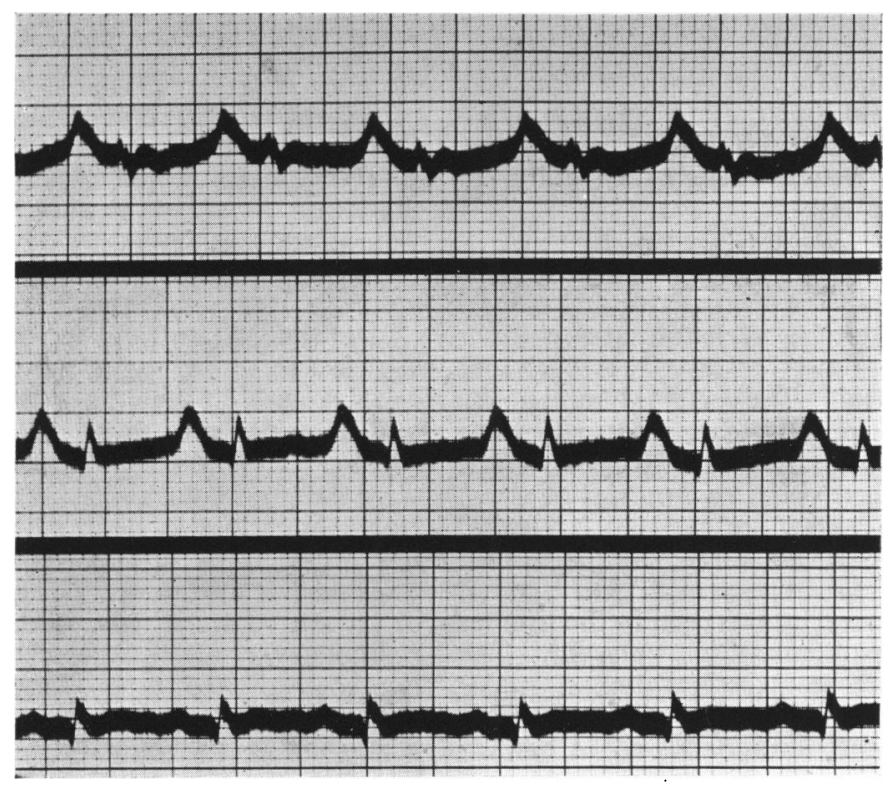

FIG. 1.-Electrocardiogram showing large $\mathbf{P}$ waves, low voltage QRS and absent $T$ waves.

recorded sinus rhythm which was regular, P 1 and 2 were huge, PR interval $0 \cdot 18 \mathrm{sec}$., QRS had a very low voltage and $T$ was flat in all leads. In view of the possibility of beriberi, $2.5 \mathrm{mg}$. thiamin was given by intramuscular injection every four hours, five times a day. The blood pyruvic acid started to fall within twenty-four hours:-

July 28, 1944, 9.15 a.m., pyruvic acid, $1 \cdot 13 \mathrm{mg}$. per $100 \mathrm{ml}$.
July $28,1944,4.0$ p.m., pyruvic acid, $1 \cdot 23 \mathrm{mg}$. per $100 \mathrm{ml}$.

July 31, 1944, 10.45 a.m., pyruvic acid, 0.70 mg. per $100 \mathrm{ml}$.

An x-ray of the chest on July 28,1944 , showed a very large cardiac shadow, the shape being consistent with a pericardial effusion (fig. 2).

The oedema and distress gradually increased. Although he had remained afebrile, in view of the 
very large heart shadow the pericardium was tapped on July 31, 1944, but only $60 \mathrm{ml}$. of a turbid yellow fluid were obtained from which pneumococci and $\mathrm{K}$. Friedländer were subsequently cultured. The boy died the next day.

Morbid anatomy. The body was that of a normally developed, moderately nourished, pale boy. There was oedema of feet, ankles and calves.

The tonsils were the size of lentils and without evidence of inflammation. The larynx, trachea and oesophagus were normal. The cervical lymph nodes were not enlarged. The thyroid was normal in size and appearance. The thymus was atrophic. Each pleural cavity contained about two ounces of clear, straw-coloured fluid. The parietal and visceral pleurae were thin, smooth and lustrous. Both lungs were moderately hyperaemic. On section some muco-purulent exudate was seen in the smaller bronchi but no consolidation was present. The paratracheal and tracheo-bronchial lymph nodes ranged in size from a hemp seed to a pea, were somewhat firm in consistency and dark red in colour.
In none was there any evidence of tuberculosis.

The pericardium contained about 2 to $3 \mathrm{oz}$. (75 c.c.) of fibrino-purulent exudate. The heart was very considerably enlarged, due mainly to a dilatation of the right auricle and ventricle which were grossly distended by dark blood. The weight of the empty heart was $125 \mathrm{~g}$. The wall of the right ventricle was very thin, 1 to $2 \mathrm{~mm}$. in thickness, that of the left ventricle 5 to $8 \mathrm{~mm}$., that of the right auricle 1 to $3 \mathrm{~mm}$. and of the left auricle 1 to $1.5 \mathrm{~mm}$. in thickness. The endocardium of the right auricle and ventricle was thick and milky in appearance (fig. 3). The trabeculae carneae of the right ventricle were extremely flattened. The myocardium of the right ventricle was definitely discernible in only a few areas, most of the wall being formed by the thickened endocardium. The trabeculae carneae of the left ventricle were moderately flattened. The pulmonary conus of the right ventricle was particularly dilated. It formed a dome-shaped aneurysm (fig. 4) and contained a reddish-grey, firmly adherent mural thrombus in size rather

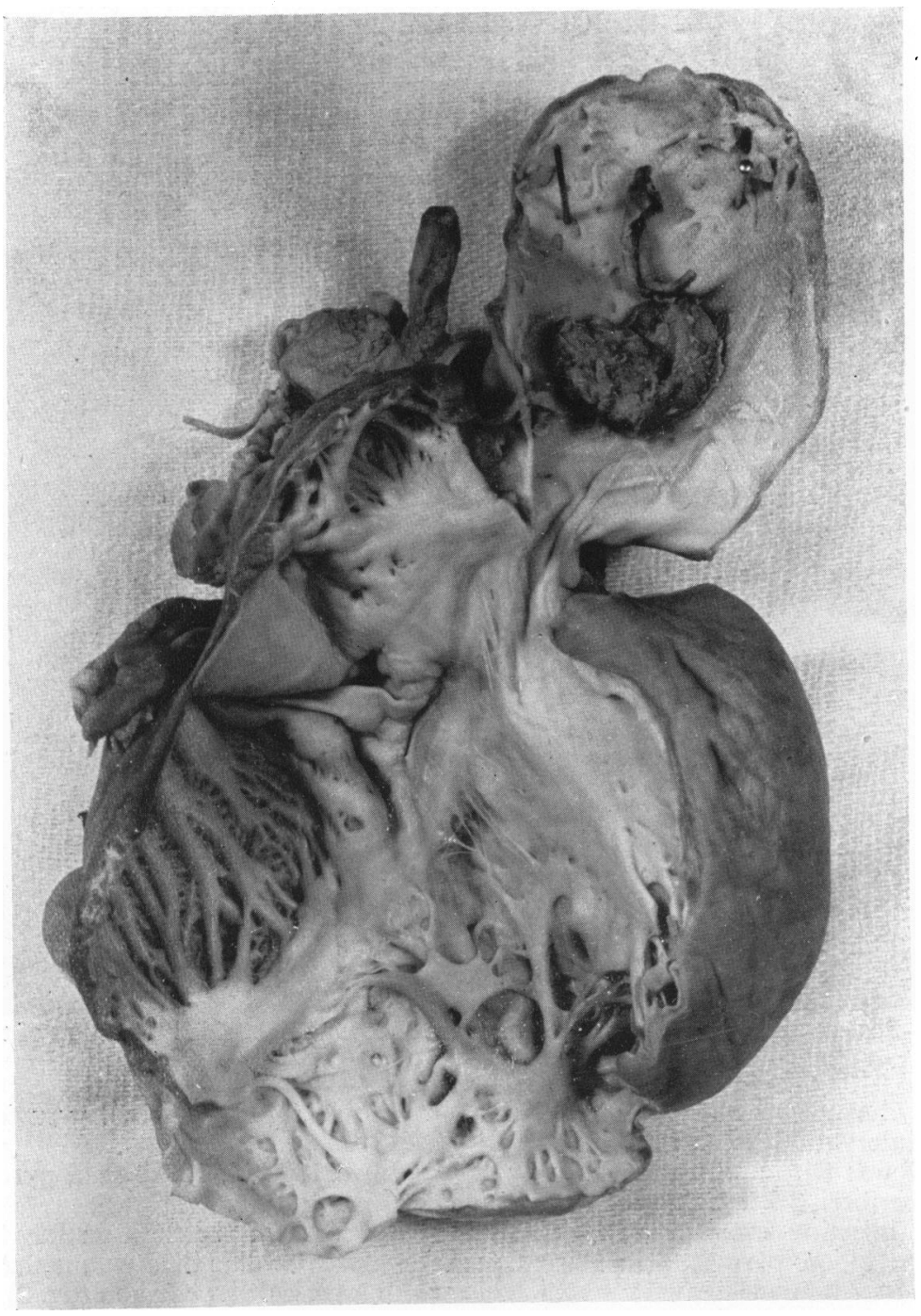

FIG. 3.-Interior of right ventricle showing endocardial thickening and parietal thrombus in aneurysm of pulmonary conus. 


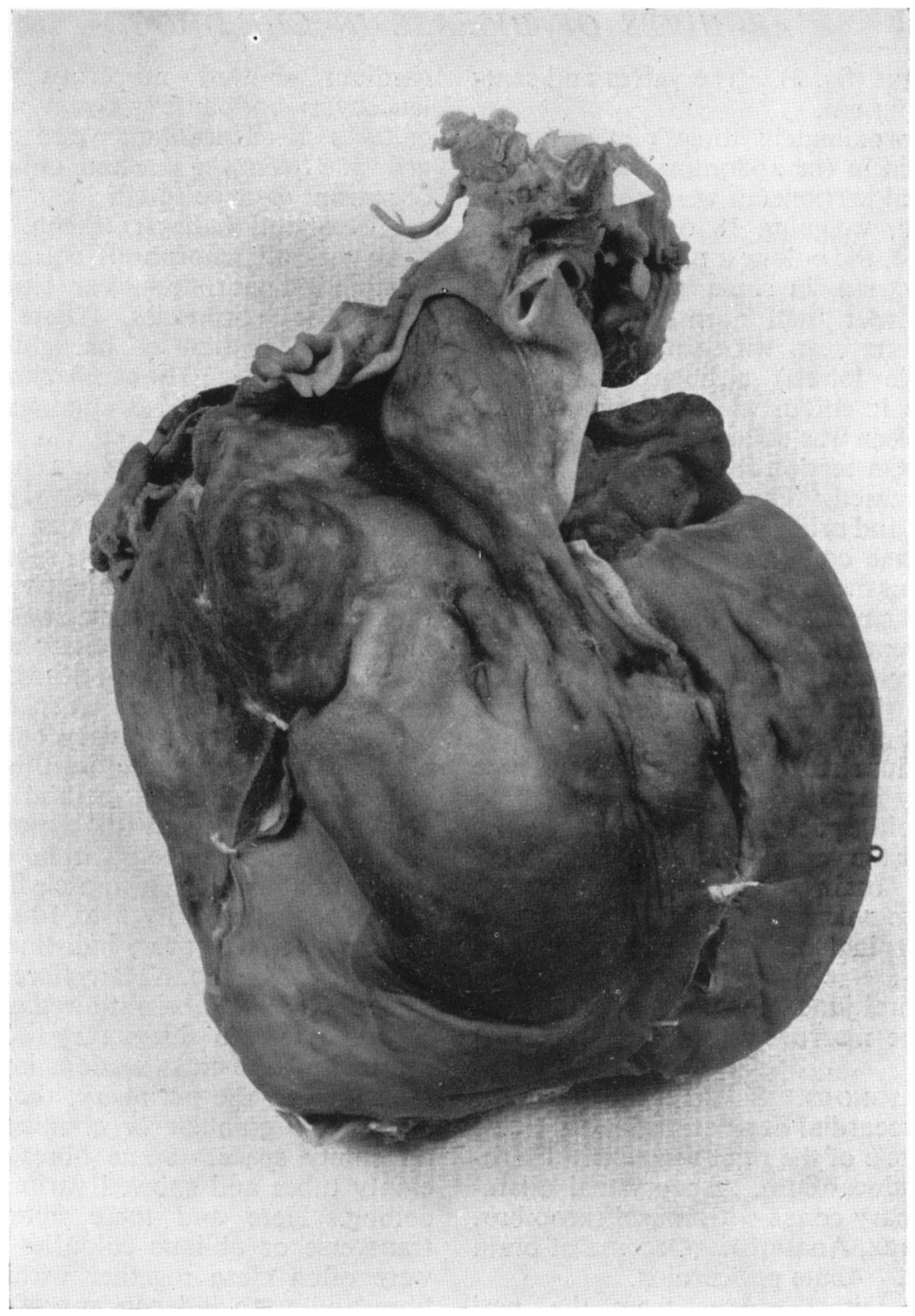

Fig. 4.- - Left oblique view of the heart showing the dilated right ventricle and the aneurysm of the pulmonary conus.

Fig. 5.-Liver. 
larger than a walnut (fig. 3). The valves and septa of the heart were normal.

There were approximately three pints of clear straw-coloured fluid in the abdominal cavity. The parietal and visceral peritoneum were normal. The liver was enlarged, weighing $18 \mathrm{oz}$. The surface was nodular (fig. 5), the colour a pale sandy yellow. The consistency varied, in some parts being very soft, in others harder than normal. On section small red areas were seen with tiny yellow spots without discernible lobular structure and much larger areas yellow in colour with a distinct lobular structure. The spleen was enlarged and fairly hard, weighing $105 \mathrm{~g}$. On section the trabecular pattern was somewhat increased. The kidneys were soft and pale. The ureters and urinary bladder were normal.

The large intestine contained semi-liquid yellow faeces. The mucous membrane was oedematous and hyperaemic. The small bowel and stomach were normal. The mesenteric lymph nodes were normal.

The gall bladder contained green bile; the bile ducts were patent. The pancreas and adrenals were normal.

The skull and dura mater were normal. There was a considerably increased amount of clear fluid in the subarachnoid space. In a few places the leptomeninges over the vertex had a somewhat milky appearance. The brain was oedematous. The venous sinuses were normal.

The spine and spinal cord appeared normal to the naked eye.

The costo-chondral junctions and the femur were normal. The bone marrow of the latter was red throughout.

ANATOMICAL Diagnosis. Subacute toxic hepatitis. Chronic myocardial degeneration with severe atrophy of the muscle of the right ventricle. Fibroelastosis of the endocardium. Aneurysmal dilatation of the pulmonary conus with mural thrombus. Ascites, Hydrothorax, Anasarca. Oedema of brain and leptomeninges. Acute pericarditis.

BACTERIOlOGY. Direct smears from the peri- cardium showed numerous polymorphonuclear leucocytes and a few Gram negative bacilli. In cultures K. Friedländer and pneumococci were grown. From the intestine only lactose fermenting organisms were cultured.

Histological findings. LUNG. In several bronchi there was an amorphous eosinophil material containing polymorphonuclear leucocytes and a few red blood corpuscles. There was a moderate cellular infiltration of bronchial walls and peribronchial tissue. The capillaries of the interalveolar septa were dilated and engorged, the alveoli were empty.

TONSIL. No inflammatory changes.

HEART. Sections from right auricle, right ventricle, pulmonary conus, left auricle, left ventricle and interventricular septum were examined. The subendocardial connective tissue, especially that of the right ventricle, was very considerably increased in amount, and consisted of faintly eosinophil, ill-demarcated fibres, with thin fusiform nuclei, surrounding vacurlar spaces and thus causing a resemblance to a honeycomb (fig. 6). Many elastic fibres were seen in this layer in sections stained by the Weigert method (fig. 7). Occasionally a blood vessel with a wall showing hyaline degeneration was seen within the thickened subendocardial tissue. The muscle fibres were extremely atrophic, the majority 5 to $10 \mu$ in diameter, their transverse striation very indistinct or not discernible at all (figs. 8 and 9). Many fibres had a spiral shape. The longitudinal fibrils showed a variety of changes. In some muscle fibres they were well developed throughout the cross section, in others fibrils were seen only in the periphery, the central part being either pale granular or completely colourless like an empty space. Some fibres resembled entirely empty tubes and showed various degrees of spiral coiling. Here and there fibres were seen with transverse or oblique colourless lines. Such lines were often close together within a single muscle fibre and were independent of the "Kitt Linien."

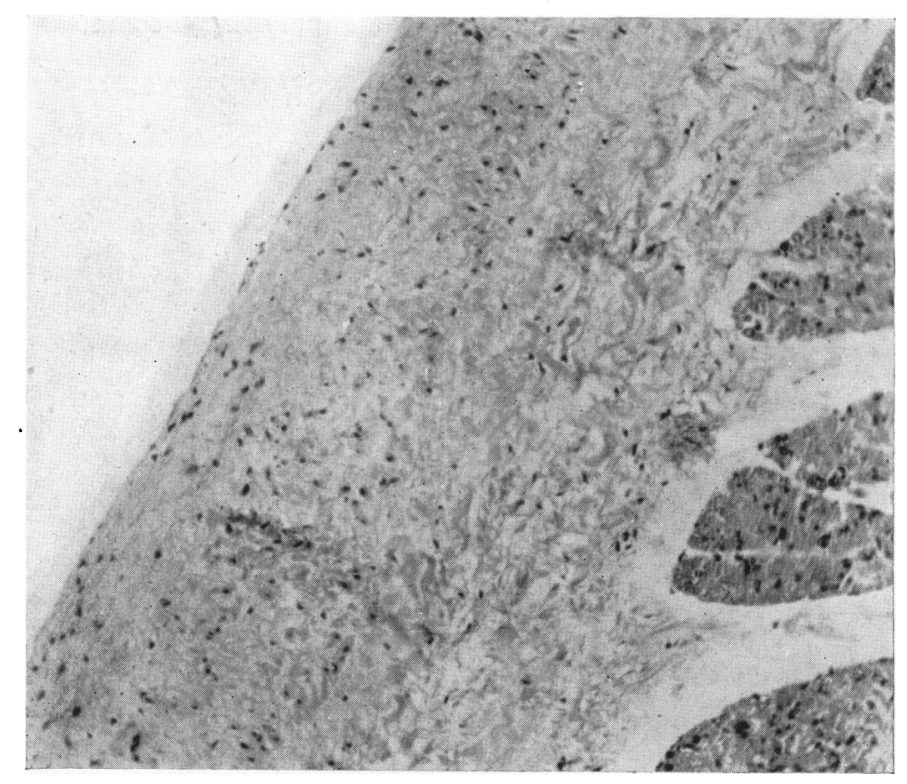

FIG. 6.-Thickened endocardium of right auricle. Haematoxylin and eosin. $\times 150$. 


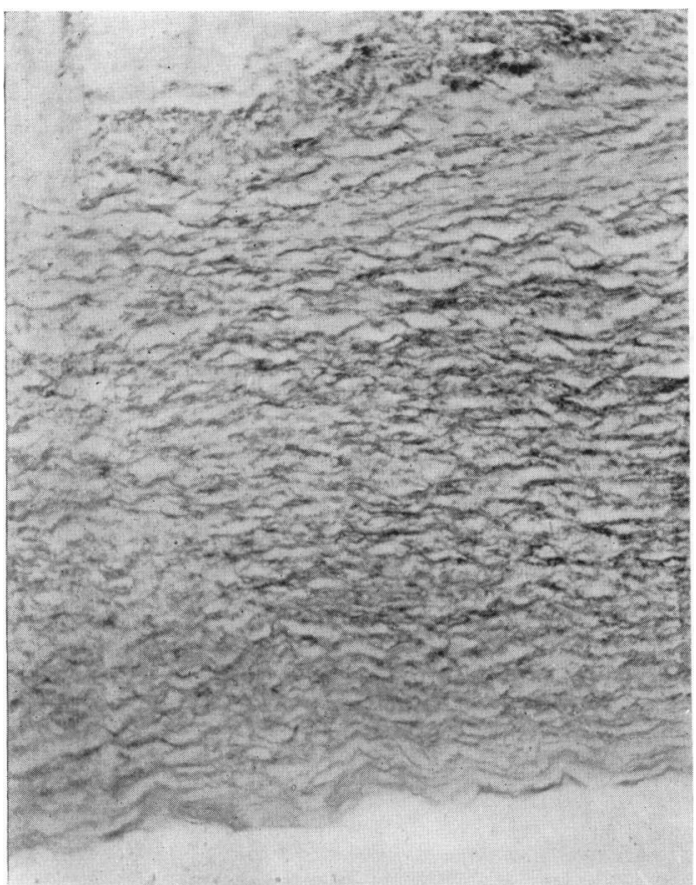

FIG. 7.-Thickened endocardium of pulmonary conus. Weigert's elastic tissue stain. $\times 150$.

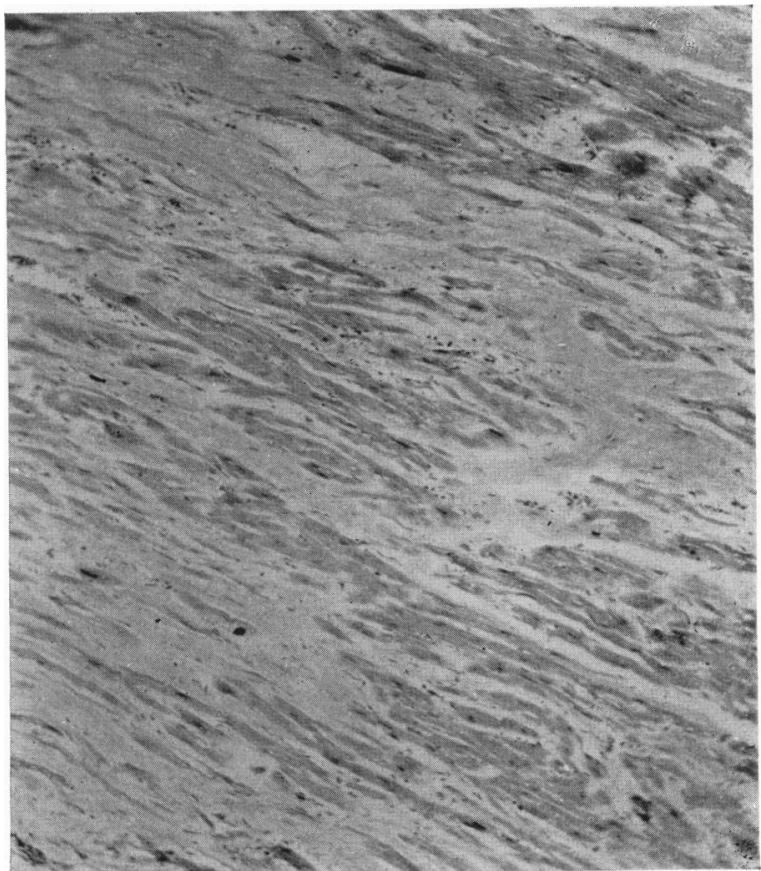

Fig. 8.-Interventricular septum. Haematoxylin and eosin. $\times 85$.

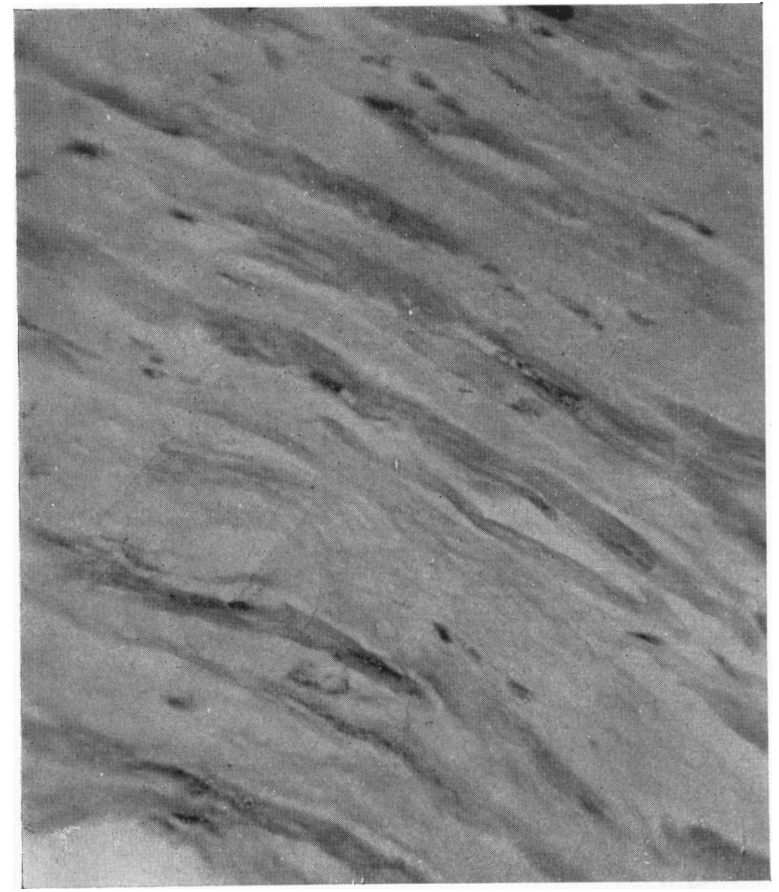

FIG. 9.-Interventricular septum. Haematoxylin and eosin. $\times 380$.

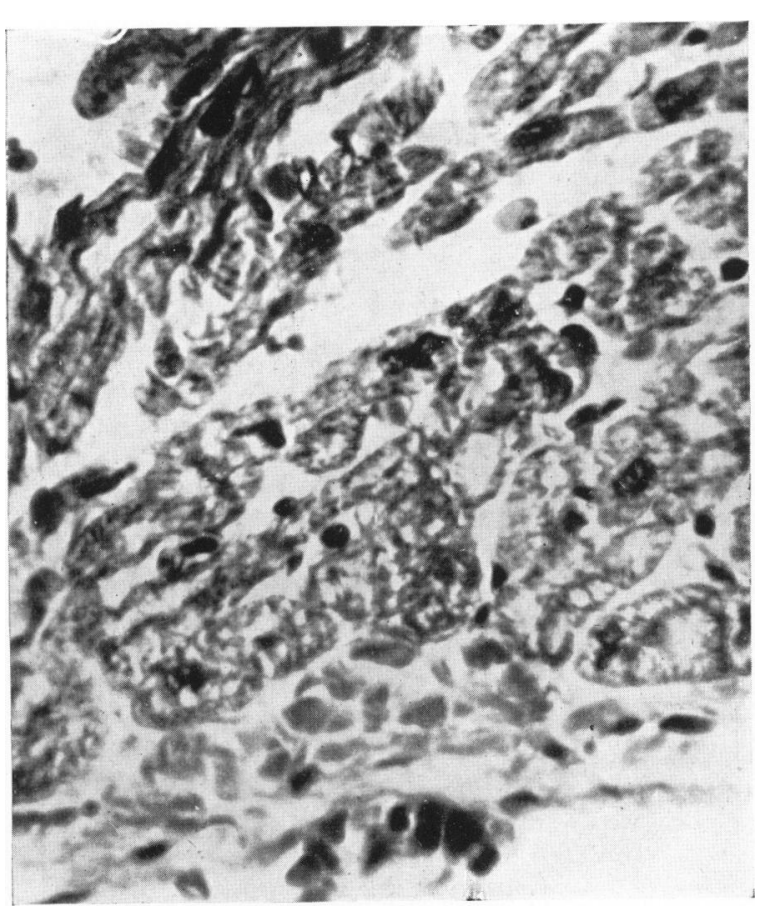

FIG. 10.-Left ventricle. Haematoxylin and eosin. $\quad \times 670$. 


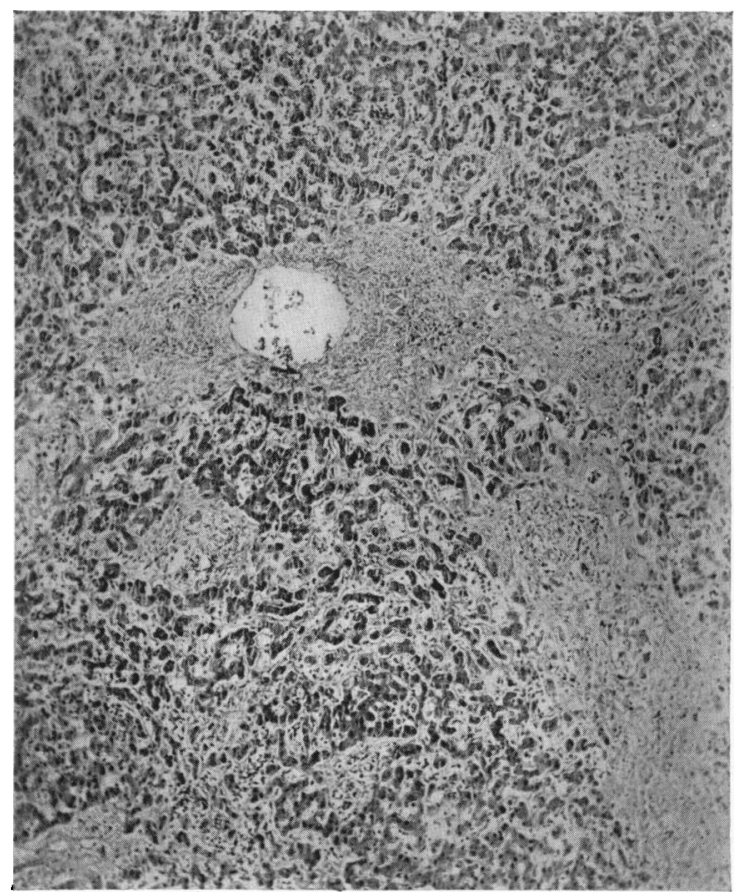

FIG. 11.-Liver. Haematoxylin and eosin. $\times 85$.

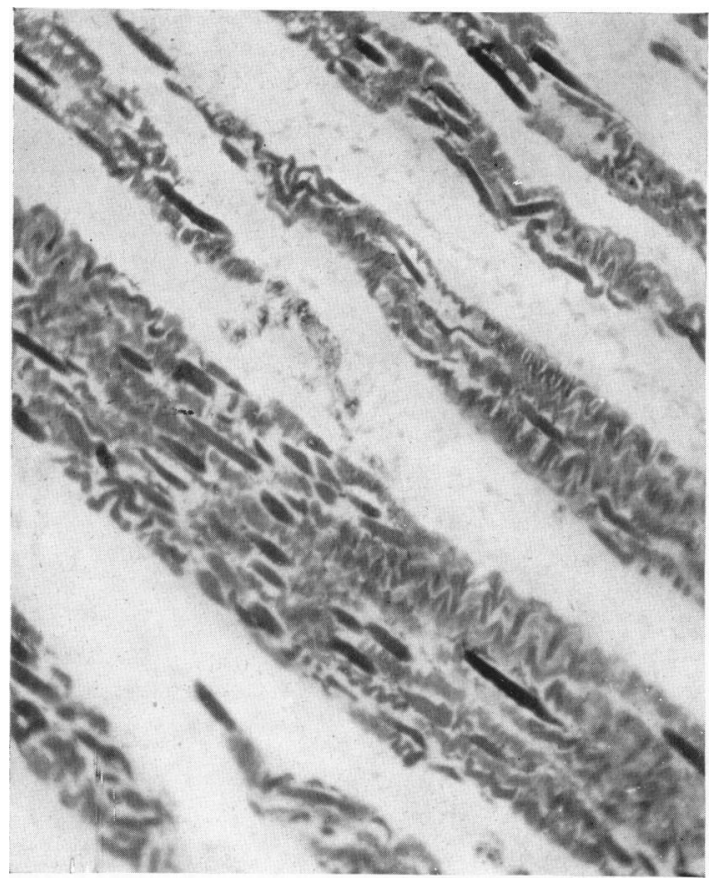

FIG. 13.-M. Quadriceps femoris. Haematoxylin and eosin. $\times 85$.

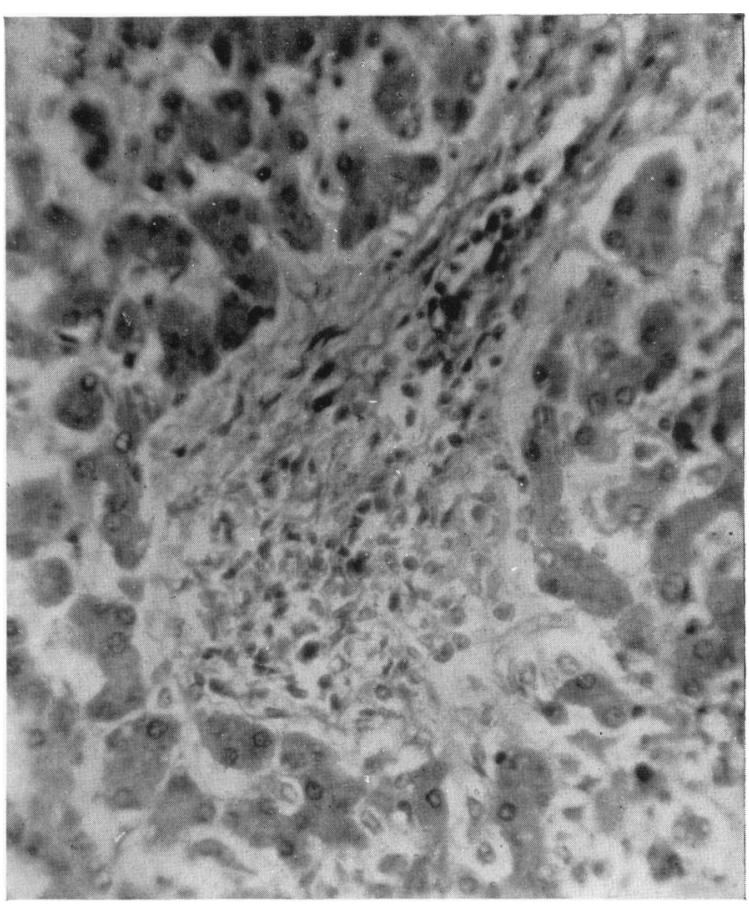

FIG. 12.-Liver showing periportal space with cellular infiltration. Haematoxylin and eosin. $\times 380$.

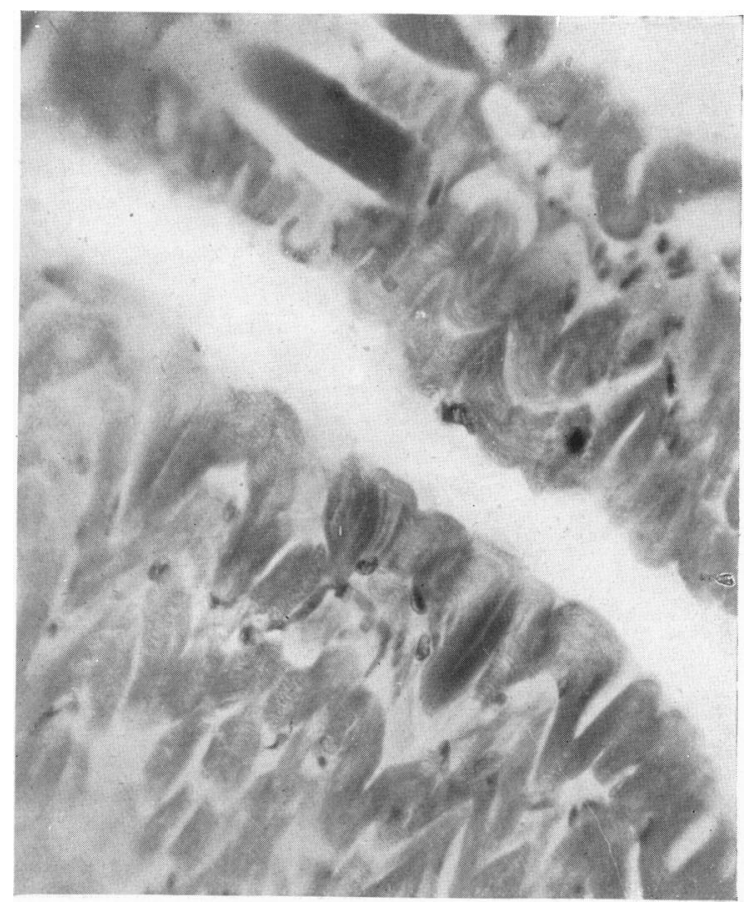

FIG. 14.-M. Quadriceps femoris. Haematoxylin and eosin. $\times 380$.

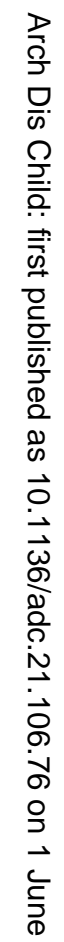

$\vec{\oplus}$

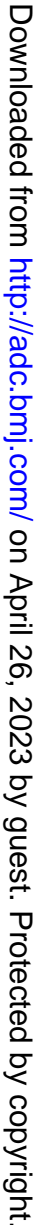




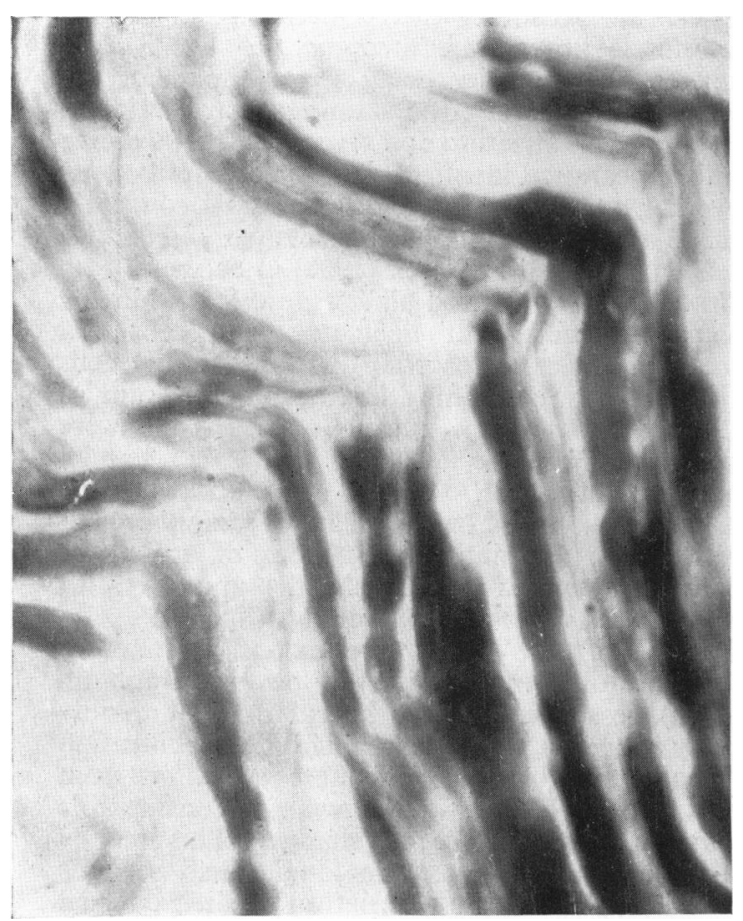

Fig. 15.-Femoral nerve. Weigart-Pal. $\times 670$.

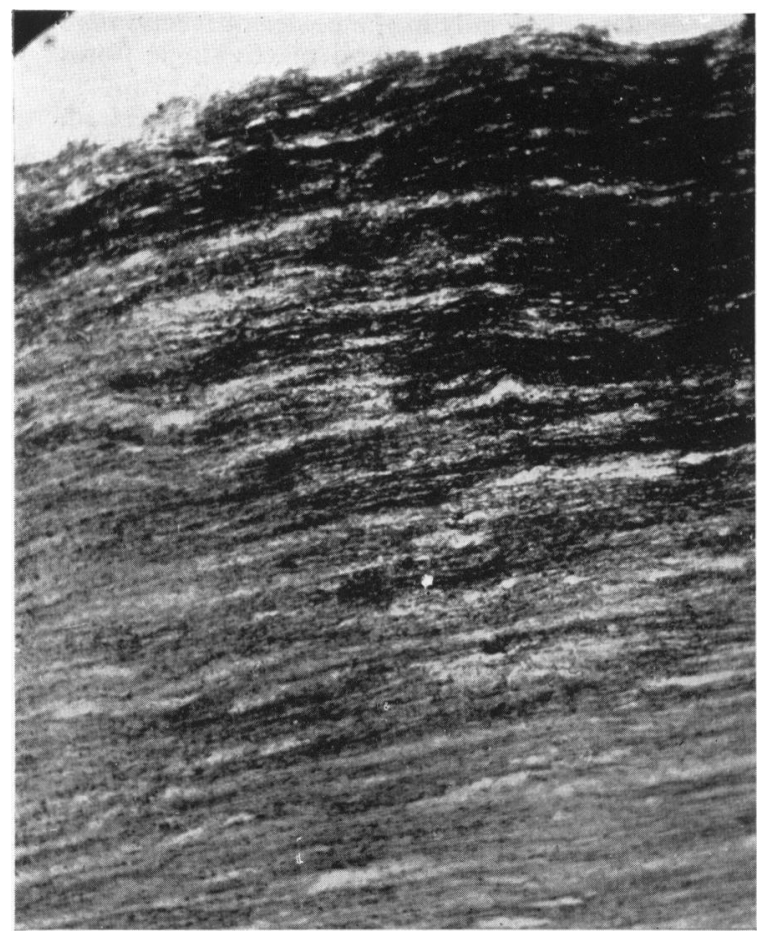

Fig. 17.-Spinal cord, longitudinal section. Weigert-Pal. $\times 85$.

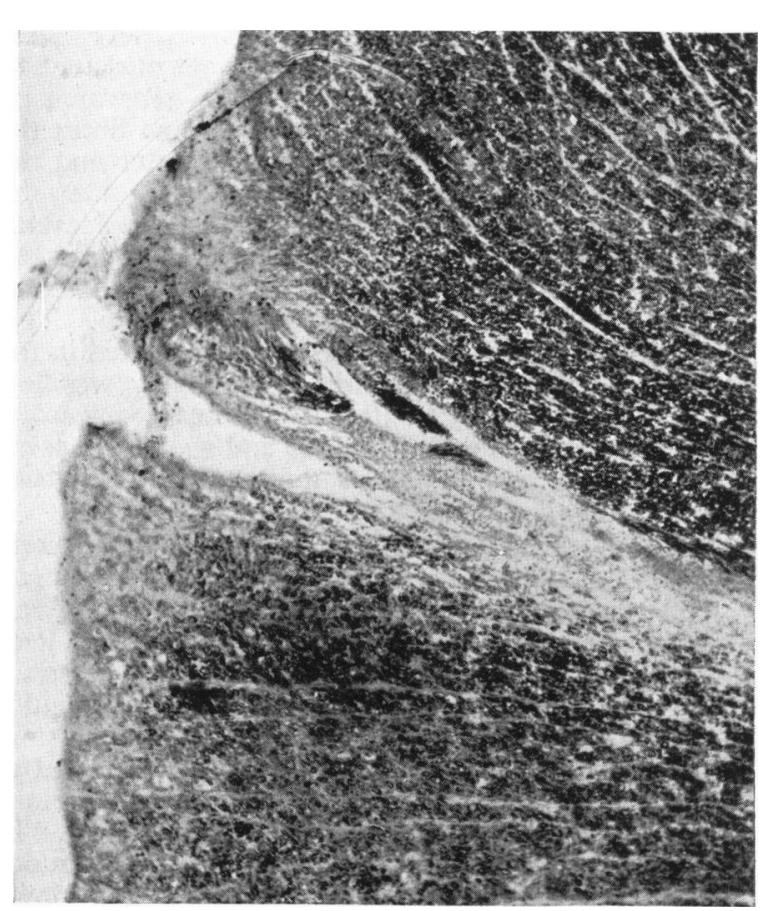
FIG. 16.-Spinal cord, posterior column. Weigert-Pal.

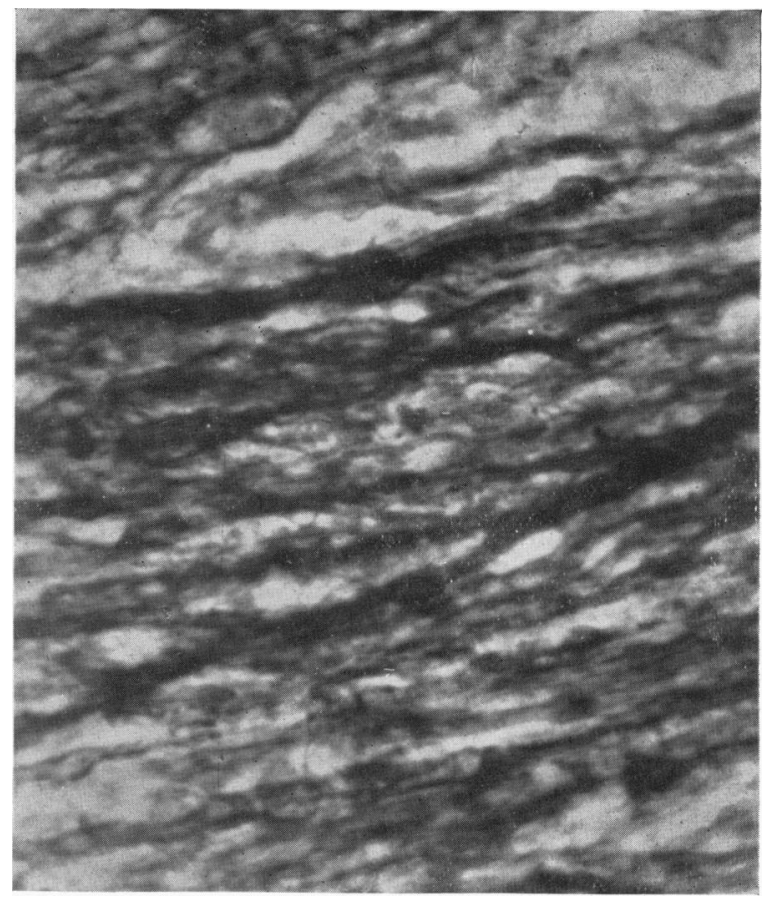

Fig. 18.- Spinal cord, longitudinal section showing balloonlike swelling of myelin sheaths. Weigert-Pal. $\times 670$.

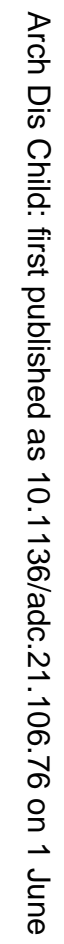

$\vec{\omega}$

के

응

高

혹 
The nuclei had irregular outlines and many showed large spherical colourless areas. Where such changes were most marked the whole nucleus had a foamy appearance with 'vacuoles' separated by thin strands of basichromatin. In some fibres the nuclei filled the whole transverse diameter and the fibres were bulging at this site, showing that the fibre had previously been thicker. In several places the fibres appeared fragmented or merged gradually into a shapeless, granular eosinophil mass in which tiny fusiform nuclei were seen. This hydropic degeneration was especially marked in the subendocardial fibres, while the atrophy was less marked in this region (fig. 10). The subepicardial areolar tissue was oedematous and showed in some areas a diffuse, in others a more circumszribed, infiltration with small round cells.

LIVER. The structure of the liver was completely distorted. No normal lobuli with radially arranged cell trabeculae and a central vein were seen. Instead patches and strands of irregularly arranged liver cells were observed separated by a network of broad strands of connective tissue (fig. 11). The pieudolobuli were in most places smaller than normal lobuli, their shape showed a great variation and in the majority no central vein was visible while in a few an eccentric intralobular vein was present. In some places there was no formation of pseudolobuli; only small groups of liver cells or even single liver cells were seen within a young granulation tissue of periportal origin. The liver cells within the pseudolobuli showed some atrophy due to a dilatation of the capillaries and a moderate number of vacuoles in their cytoplasm. The isolated groups of liver cells showed severe degenerative changes. The Kupffer cells appeared normal. The periportal tissue was considerably increased in amount and formed in sections broad ramifying strands and islands. Its appearance was variable; in some parts it consisted mainly of fibroblasts and collagenous fibres, in other parts there was a marked infiltration with small round cells (fig. 12). The appearance of the bile ducts was normal and there was only a very moderate bile duct proliferation. The arteries and veins were normal. Sections stained by the trichrome method showed a well-preserved network of reticulum fibres. Frozen sections stained by the Herxheimer method showed numerous fat droplets in the liver cells.

KIDNEY. The glomeruli were normal. The epithelium of the first convoluted tubules was swollen, granular and, here and there, a granular eosinophil material was seen in their lumen. The veins of the medulla were distended and engorged.

SPLEEN. The Malpighian bodies were small and consisted almost entirely of germinal centres surrounded by a narrow ring of mature lymphocytes. Here and there were tiny deposits of extravascular hyaline material within the follicles. The venous sinuses were distended and engorged. Red blood corpuscles were also seen within the cords of Billroth. The trabecular tissue was rather conspicuous, the blood vessels were normal.

Pancreas. Structure normal. The secretory cells contained numerous zymogen granules.

Thyroid, Adrenal, Pituitary, and Thymus were all normal.

SkIN. The epidermis was stretched, the stratum papillare partly obliterated and the cutis vera oedematous.
Skeletal musCle. (M. Quadriceps femoris.) The muscle fibres were atrophic, 7.5 to $25 \mu$ in diameter, the majority being $15 \mu$. Some of the fibres showed a faint eosin staining, many an indistinct transverse striation and several had a wave-like spiral appearance identical with that described by Meyenburg (1929) in a case of amyotonia congenita (figs. 13 and 14). A similar but less marked change has been depicted by Dürck (1908) in beriberi.

BONE MARROW showed almost pure fatty marrow with small islands of haematopoietic cells. In some areas there were groups of large round cells with cytoplasm containing fine eosinophil granules and an eccentric dark nucleus. These cells were apparently embryonic fat cells.

Peripheral Nerve. (Branch of Femoral Nerve.) The nerve fibres showed areas of complete demyelinization alternating with areas of grossly or moderately swollen myelin sheaths and areas of circumscribed balloon-like swellings (fig. 15).

SPINAL CORD. There were extensive areas of demyelinization mainly in the posterior column (fig. 16), less severe in the lateral tracts and only slightly in the anterior tracts. This demyelinization was patchy in distribution, different sections from the same part of the cord showing a considerable variation in the degree of change. This patchy distribution was best seen in longitudinal sections of the cord, where the alternation of demyelinized and non-demyelinized areas was well shown (fig. 17). The latter sections showed also the balloon-like swellings of the myelin sheaths comparable to those in the peripheral nerve (fig. 18). The axis cylinders showed in Bielschowsky stains moderate changes in the form of tortuosity and fusiform swellings. The degeneration of axis cylinders was well shown in sections stained by Alzheimer's modification of Mann's eosin-methylene blue stain, where many axis cylinders, especially in the posterior tracts, were stained pinkish-red. In several places single fibres or groups of fibres with pink staining axis cylinders were seen among others with a dark purple stain. In the anterior horns of the spinal cord, cells were seen with disappearance of Nissl's granules and with pale or unrecognizable nuclei. The intracellular neurofibrils were preserved in some cells, disintegrated into fine granular material in others.

BraIN. The nerve cells of the cerebral cortex showed only a moderate degree of chromatolysis. In the inferior olive there were several cells showing a spherical swelling of the cytoplasm and a dark nucleus shifted to the periphery, corresponding to Nissl's 'primary irritation.' Other cells showed a very pale or scarcely recognizable nucleus.

\section{Discussion}

The gross anatomical and histological findings justified the diagnosis of beriberi for the following reasons:-

There was a combination of a severe cardiac disease without valvular involvement with degenerative changes in the nervous system.

The cardiac changes, although unusual in some respects, were exactly what one would expect to find if the acute beriberi heart or 'Shoshin,' as described by Wenckebach (1934), were to run a subacute course.

The findings in the nervous system conformed well 
with those described in typical cases of beriberi and in experimental vitamin $B_{1}$ deficiency.

To consider the cardiac changes: according to Wenckebach the characteristic findings in the acute beriberi heart were an enlargement of the whole heart, but much more of the right side than of the left, a striking dilatation and elongation of the pulmonary conus and a hydropic degeneration of the muscle fibres causing a pseudo-hypertrophy. Wenckebach claimed that the enlargement of the right heart was due to a distension by stagnating blood and the thickening of the wall to a hydropic degeneration rather than to a true hypertrophy. This claim has been challenged by other authors, especially Weiss and Wilkins (1936). Our case dees not afford a basis for taking part in this discussion. The main gross anatomical findings, the principal involvement of the right heart and the dilatation of the pulmonary conus were in agreement with Wenckebach's description of a typical beriberi heart. Most of the histological findings, like vacuolar degeneration, shifting (real or apparent) of the fibrils towards the periphery, forming of empty tubes, etcetera, were identical with those which Wenckebach described and supported by photographs. The degenerative atrophy of the muscle fibres, which resulted in the wall of the right ventricle being thinner than normal instead of thicker, may have developed after a previous real hypertrophy or, more likely, after a pseudohypertrophy due to hydropic swelling. This again conformed with the comparatively long duration of the illness.

Dürck (1908), in his classical monograph on the morbid anatomy of beriberi, described cases, some with hypertrophy of the heart, others with an atrophy of the heart muscle, and an occasional case in which there was evidence that an atrophy developed secondary to a primary hypertrophy.

The pericarditis was a recent one, obviously a terminal complication. There was no evidence of acute or chronic endocarditis or myocarditis. The valves were normal. No congenital anomaly was detected.

The unusual findings in our case, the aneurysmal dilatation of the conus with the formation of a parietal thrombus and the fibro-elastosis of the endocardium were easily explained by the fact that Wenckebach's patients were acute whereas ours ran a subacute course. The changes in the pulmonary conus were only an exaggeration of those described by Wenckebach. while the fibro-elastosis represented the reaction of the heart to prolonged passive distension and was occasionally observed in lesser degree by Dürck.

Mural thrombi in the auricles were described by Ashburn and Lowry (1944) in experimental thiamin deficiency. In man a syndrome of cardiac hypertrophy, dilatation with the presence of mural thrombi, has been described by a number of observers. Dock (1940) reported five fatal cases, in three of which the diagnosis of beriberi was deemed to be established and considered to be possible in the other two. Smith and Furth (1943) recorded five similar cases and reviewed the literature. The essential pathological features were an endocardial and myocardial fibrosis with cardiac hypertrophy and dilatation in the absence of vascular or valvular damage. Considering its etiology they were of the opinion that the causation was a nutritional deficiency, but were unable to say that vitamin B was the factor responsible. On the other hand, Levy and von Glahn (1944), who described ten fatal cases of uncomplicated cardiac hypertrophy, dilatation with mural thrombi in the ventricles, found no evidence that a vitamin deficiency contributed to the cause. Although the histological changes were not identical there was a definite similarity between the three series of cases, which lends support to the observation of Weiss and Wilkins (1936), that hydropic degeneration of cardiac muscle fibres is not absolutely specific for beriberi. Only the totality of the anatomical and histological findings in the heart and in the nervous system can justify the diagnosis of beriberi in a sporadic case.

The changes in the nervous system in beriberi have been more extensively studied than those in the myocardium. Several authors have compared the neurohistology of beriberi with pellagra. Although there is still some controversy as to whether the neurohistology of beriberi is specific for this disease and due to a thiamin deficiency or is a result of starvation (Spillane, 1945), there is close agreement with regard to the principal microscopical findings in the nervous system of beriberi cases. Dürck (1908), Rodenwaldt (1908), Winkelman (1926), Cannon (1929-30), Shimazono (1931), Langworthy (1931), Zimmerman and Cowgill (1937), Zimmerman (1939-40) and Hsü YingK'Uei (1942) all describe myelin degeneration, demyelinization, degeneration of axis cylinders in the peripheral nerves and in the fasciculi of the spinal cord. The involvement is described as progressing from the periphery towards the centre, the sensory fibres are more involved than the motor and the thick fibres more than the thin. In the spinal cord Rodenwaldt stressed the degeneration of the column of Burdach. A patchy distribution of the degeneration appears to be rather characteristic. Dürck states that the myelin degeneration within the continuity of a single fibre is always spotty and segmentary and that one fibre may be quite intact over part of its length while in various other parts advanced disintegration, fatty metamorphosis and resorption of the myelin may be observed. The findings in our case are, so far as nerve fibres are concerned, of the same nature as those described in authentic cases from endemic areas. There is less conformity in the literature with regard to the nerve cells than to the nerve fibres. Nissl's 'primary irritation,' observed in a few places in our case, belongs according to Zimmerman and to Hsü Ying-K'Uei to the pellagra and not to the beriberi syndrome. The hyalinization of the walls of blood vessels and the 'diffuse parenchymal fatty degeneration' observed by Winkelman in pellagra were not 
seen in our case. The primary irritation is characteristic of retrograde degeneration (Spielmeyer, 1922) and it is not surprising to meet this change in beriberi.

The severity of the degenerative changes in the skeletal muscle of our case is remarkable.

An unusual finding was the cirrhosis of the liver. Typical cases of beriberi with cirrhosis of the liver have not been described to our knowledge, nor was liver cirrhosis produced experimentally by thiamin deficiency. The problem of nutritional cirrhosis of the liver has been thoroughly studied in recent years by György and Goldblatt (1939), Lillie, Daft and Sebrell (1941), Himsworth and Glynn (1944) and others. The existence of a liver cirrhosis due to a nutritional deficiency can be considered as well established. It is not known whether a specific vitamin can be made responsible for cirrhosis of the liver and it is certain that other factors like the relation of fat to protein in the diet play an important rôle in the development of nutritional liver disease. It is, therefore, not justified to consider the changes in the liver as due to the same cause as those in the myocardium and in the nervous system. They are rather to be attributed to another associated dietary deficiency.

As the liver disease was of long standing it is possible that it contributed to the development of a vitamin B deficiency state. In cases of liver damage there is a high urinary excretion of thiamin following a series of oral loading doses, amounting in some cases to 50 per cent. of the dose given, normal figures being about 20 per cent. (Allibone and Finch, 1945). In our patient there was no question of a dietary thiamin deficiency. When first seen his diet contained at least $0.75 \mathrm{mg}$. thiamin a day, which rose after his first admission to $0.9 \mathrm{mg}$. a day, exclusive of medication which was intermittent. Knott (1936) considered an intake of 60 microgm. per kilo body weight to be optimal. On this basis the optimal daily thiamin intake for our patient, who weighed $30 \mathrm{lb}$., would have been $0.8 \mathrm{mg}$. The adequacy of the diet, together with the rarity of beriberi in England, indicates the severity of the metabolic dysfunction which led to the deficiency.

At the time of the boy's first admission the low plasma protein and the hypocalcaemia suggested a nutritional deficiency state. Although the blood pyruvic acid level was definitely raised beriberi was not further considered. On readmission the overshadowing syndrome of congestive heart failure in a child of three and a half years without evidence of valvular heart disease and who previously had had symptoms of nutritional deficiency, cause investigations and treatment to be concentrated on the beriberi aspect of the clinical picture. The cases of myocardial fibrosis described by Dock (1940), Smith and Furth (1943) and Levy and von Glahn (1944) were all fatal. A characteristic of these patients was the failure to respond to vitamin therapy and although remissions might occur, these seemed to be spontaneous. Although the fall of the blood pyruvic acid level with vitamin B therapy in our boy was as rapid as could be expected, he too went rapidly downhill. The morbid histology of the heart seems to explain adequately the course of such cases.

Wenckebach (1934) commented on the surprising rapidity with which symptoms of acute beriberi heart (Shoshin) develop and the equal rapidity with which they may be alleviated. It is nevertheless remarkable that a boy with such chronic and irreversible cardiac damage could have been active and running about until eight days before he died.

The typical radiological configuration of rightsided cardiac dilatation, as described by Wenckebach, was partly masked by the 4 to $5 \mathrm{oz}$. of fluid in the pericardium.

There is no unanimity as to the form of the electrocardiogram in beriberi. Wenckebach (1934) in Java found no essential change, nor did Keefer (1930) in China. Neither Jones and Bramwell (1939) nor Konstam and Sinclair (1940) saw anything gross in the electrocardiogram of their cases. In experimental thiamin deficiency Williams et al. (1940) observed flattening of the $T$ wave which became larger when vitamin was added to the diet. Weiss and Wilkins (1936) found changes in the $\mathrm{T}$ wave, a prolonged $\mathrm{Q}-\mathrm{T}$ and a low voltage $\mathrm{QRS}$. in over 90 per cent. of their cases. Goodhart and Jolliffe (1938) noted depression of the S-T segments and inverted $T$ waves in their cases. Dock (1940) recorded alteration of the ventricular complex suggestive of a myocardial infarct. It seems likely that the abnormalities are proportional to the degree. of chronic or permanent damage.

The very large $P$ wave in our patient, particularly when compared with the absent $T$ wave suggested a. hypertrophy of the auricles, a condition which may occur when they are subject to undue stress by a failing ventricle. Why the auricle should be capable of undergoing hypertrophy while the ventricular muscle degenerates is unknown. An accentuated $P$ wave was observed by Smith and Furth (1943) in one of their fatal cases of chronic myocarditis attributed to nutritional deficiency.

\section{Summary}

A fatal case of beriberi is described. The relationship of the myocardial changes to those found in acute beriberi and in myocardial fibrosis is discussed.

Thanks are due to Sir Leonard Parsons for criticism and advice, to Dr. A. V. Neale for permission to publish the case and to Dr. E. M. Hickmans for the photographs.

\section{REFERENCES}

Allibone, E. C., and Finch, E. (1945). Arch. Dis. Childh., 20, 169.

Ashburn, L. L., and Lowry, J. V. (1944). Arch. Pathol., $37,27$.

Bates, J. (1941). Lancet, 1, 176.

Cannon, A. (1929-30). Trans. Roy. Soc. Trop. Med. Hyg., 23, 263.

Dock, W. (1940). Trans. Ass. Amer. Physicians, 55, 61.

Dürck, H. (1908). Untersuchungen über die pathologische Anatomie der Beriberi. Suppl. der Beiträge zur pathologischen Anatomie, Jena. 
Ellis, R. W. B. (1945). Arch. Dis. Childh., 20, 97.

Goodhart, R., and Jolliffe, N. (1938). Amer. Heart J., $15,569$.

György, P., and Goldblatt, H. (1939). J. exper. Med., $70,185$.

Himsworth, H. P., and Glynn, L. E. (1944). Lancet, 1, 457.

Hsü Ying-K'Uei (1942). Arch. Neurol. Psychiat., Chicago, 48, 271.

Jones, A. M., and Bramwell, C. (1939). Brit. Heart J., 1, 187.

Keefer, C. S. (1930). Arch. intern. Med., 45, 1.

Knott, E. M. (1936). J. Nutrit., 12, 597.

Konstam, G., and Sinclair, H. M. (1940). Brit. Heart J., 2, 231 .

Langworthy, O. R. (1931). Brain, 54, 291.

Levy, L., and von Glahn, W. C. (1944). Amer. Heart J., 28, 714 .

Lillie, R. D., Daft, F. S., and Sebrell, W. H. (1941). Publ. Hlth. Rep., Washington, 56/1, 1255.
Meyenburg, H. von. (1929) in Henke and Lubarsch: Handb. path. Anat. u. Histol., 9, Part 1, Berlin.

Pyke, M. (1945). Brit. med. J., 2, 839.

Rodenwaldt, E. (1908). $\quad$ Arch. Schiffs-u Tropen Hyg., 12, 31.

Shimazono, J. (1931). Erg. inn. Med. Kinderh., 39, 1.

Smith, J. J., and Furth, J. (1943). Arch. intern. Med., 71, 602.

Spielmeyer, W. (1922). Histopathologie des Nervensystems, Berlin.

Spillane, J. W. (1945). Lancet, 2, 449.

Weiss, S., and Wilkins, R. W. (1936). Trans. Ass. Amer. Physicians, 51, 341.

Wenckebach, K. F. (1934). Das Beriberi-Herz, Berlin.

Williams, R. D., Mason, H. C., Wilder, R. M., and Smith, B. J. (1940). Arch. intern. Med., 66, 4.

Winkelman, N. W. (1926). Zeit. ges. Neurol. Psychiat., $102,38$.

Zimmerman, H. M. (1939). Yale J. Biol. Med., 12, 23. and Cowgill, G. R. (1937). Arch. Neuro!. Psychiat., $37,286$. 